(2) Open Access Full Text Article

ORIGINAL RESEARCH

\title{
Analysis of the Status Quo and Influencing Factors of Community Residents' Awareness of Basic Life Support and Willingness to Attempt Rescue
}

\author{
Yu-Fei Qian' \\ Gui-Ling Geng' \\ Yu-Qin Ren ${ }^{2}$ \\ Xin-Tong Zhang ${ }^{2}$ \\ Wen-Jun Sun ${ }^{2}$ \\ Qing $\mathrm{Li}^{2}$
}

'Department of School of Nursing, Nantong University Medical School, Nantong, 22600I, People's Republic of China; ${ }^{2}$ Department of Emergency, Nantong First People's Hospital, Nantong, 226006, People's Republic of China
Correspondence: Gui-Ling Geng Department of School of Nursing, Nantong university Medical school, No. 19, Qixiu Road, Nantong City, Jiangsu Province, 22600I, People's Republic of China

Tel +86 I5I52889466

Fax +86-5I3-8505I876

Email geng_gl@I26.com
Objective: This study aimed to investigate community residents' awareness of basic life support (BLS) and their willingness to attempt rescue.

Methods: From October to December 2020, in the communities of Nantong City, a stratified three-stage random sampling method was adopted to select residents from 12 neighborhood committees over the age of 18 with whom to conduct a cross-sectional questionnaire survey. A self-designed questionnaire was adopted, the contents of which included the general situation of the respondent, knowledge, attitude, and behavior in relation to BLS; the Cronbach's $\alpha$ coefficient of the questionnaire was 0.719 .

Results: A total of 3000 questionnaires were distributed, of which 2812 were valid, with a valid response rate of $93.73 \%$. Of the 2812 respondents, $41.18 \%$ had seen an automatic external defibrillator (AED), $48.83 \%$ had experience of' cardiopulmonary resuscitation (CPR), and $25.07 \%$ of the respondents had experience of' AEDs. When an accident occurred, $50.50 \%$ of residents were willing to attempt rescue, $70.80 \%$ were willing to attempt rescue under professional guidance, and $71.23 \%$ were willing to attempt rescue after learning BLS techniques. Of the residents who were unwilling to attempt rescue, $32.75 \%$ were worried about their lack of ability, $27.91 \%$ were concerned about legal issues, $14.01 \%$ feared infectious diseases, and $10.35 \%$ were unwilling to perform mouth-to-mouth artificial respiration. Age, occupation, education level, and whether they had participated in first aid training were the influencing factors.

Conclusion: Residents in Nantong have less knowledge of BLS, and their knowledge of CPR is better than that of AEDs. Residents have a strong willingness to learn BLS. Measures need to be taken to improve their understanding of BLS and their application skills. Residents have high levels of willingness to attempt rescue, but a certain percentage of residents have concerns. Interventions can be made to target the different reasons.

Keywords: out-of-hospital cardiac arrest, basic life support, automatic external defibrillator, rescue willing

\section{Introduction}

Sudden cardiac death (SCD) refers to death induced by heart-related causes within one hour of the onset of acute symptoms and is characterized by the sudden loss of consciousness. ${ }^{1}$ The direct cause of SCD is cardiac arrest (CA). In China, 2.5 million patients die of CA every year, ranking first in the world ${ }^{2}$, and $80 \%$ of CA cases occur out of hospital; 2,3 the survival rate after an out-of-hospital cardiac arrest (OHCA) is less than $1 \%$ in China. ${ }^{4}$ For OHCA patients, the key to their survival is timely cardiopulmonary resuscitation (CPR) and electrical defibrillation, 
which constitute basic life support (BLS). ${ }^{5,6}$ A previous study revealed that early, timely, and effective BLS can improve the survival rate of patients by $30 \%{ }^{7}$ Although Chinese residents have a low awareness of CPR and automatic external defibrillators (AED), ${ }^{8-10}$ there is no specific guidance on the technicalities and use of AEDs. Therefore, in order to understand community residents' willingness to learn BLS techniques and rescue in the face of accidents, a survey was conducted to provide basic data for the establishment of a residents' BLS training management program suitable for China's national conditions.

\section{Data and Methods}

\section{General Information}

From October to December 2020, a cross-sectional questionnaire survey was conducted among urban residents in Nantong. Inclusion criteria for the subjects: (1) age $\geq 18$ years old, providing informed consent; (2) the ability to listen, speak, read, and write; (3) must have been living in Nantong for more than one year. Exclusion criteria: (1) severe visual and auditory impairments, and mental illness that make it difficult to complete the survey; (2) cognitive impairments that make it difficult to complete the survey. This study was approved by the ethics committee of the first people's Hospital of Nantong City, and informed consent was obtained from the respondents. All participants signed a document of informed consent. The trained staff provided the instructions for the respondents and were not allowed to use guiding language.

\section{Questionnaire}

The self-designed Questionnaire of Basic Life Support for Community Residents was used (Supplementary data). This questionnaire consists of four parts: the first part is a survey of the general situation of the respondents, including gender, age, educational background, occupation, and whether they had participated in or performed first aid; the second part is a survey of public awareness of BLS, including knowledge of AED and CPR and whether they had received training; the third part is a survey of the attitude of the respondents to BLS; the fourth part is a survey of public BLS behavior, including whether they were willing to rescue CA patients, learn BLS-related knowledge, or rescue patients after receiving BLS training, and the reasons for each. The questionnaire has been tested for reliability and validity, the Cronbach's a coefficient of the questionnaire to test its internal consistency is 0.719 , and the Cronbach's a coefficients for sub-questionnaires "Resident's knowledge of BLS" is 0.736 , the Cronbach's a coefficients for sub-questionnaires "Resident's attitude of BLS" is 0.704, and the Cronbach's a coefficients for subquestionnaires "Resident's practice of BLS"is 0.733 . The test-retest reliability is 0.707 . After two rounds of Delphi expert letter inquiries, the validity of each item content is greater than 0.83 , exploratory factor analysis, KMO value is 0.777 , Bartlett sphere test $\chi^{2}=5118.289, \mathrm{P}<0.01$, through principal component analysis, the extracted feature value is greater than 1 . The common factor of. Delete the entries with factor load less than 0.4 , the number of entries contained in the common factor is less than 3 , and the load value difference is less than 0.2. Finally, three common factors are proposed, and the cumulative variance contribution rate is 63.209\%. Basic Life Support Questionnaire: The questionnaire is divided into three parts, namely the Basic Life Support Cognition Questionnaire, the Basic Life Support Attitude Questionnaire, and the Basic Life Support Behavior Questionnaire, with a total of 28 items. Whether the questionnaire is assigned a value, "Yes"-2 points, "No"-0 points; Attitude questions: Use the Likert 3-level scoring method, assign 1-3 points from "unwilling", "unsure" (The investigator cannot be sure whether he will be rescued) and "very willing"; single 2 points for correct selection and 0 points for errors; 2 points for correct multiple-choice questions, 1 point for incomplete answers, and 0 points for incorrect answers. The questionnaire is written using the "Questionnaire Star" App, and the researcher distributes the questionnaire $\mathrm{QR}$ code on the spot. If the respondent does not have a smartphone and cannot scan the code, he can use another person's mobile phone to fill it out. The staff will guide you during the filling process and When filling in instructions, no guiding language should be used in the process. Questionnaires filled in within 6-12 minutes were regarded as valid.

\section{Statistical Methods}

Data were statistically analyzed using SPSS 21.0 statistical software. General demographic data were treated with descriptive statistics. Measurement data were expressed as mean \pm standard deviation $(\mathrm{x} \pm \mathrm{SD})$ and evaluated using the $t$-test or analysis of variance. Count data were compared using the chi-square test. $\mathrm{P}<0.05$ was considered statistically significant. The influencing factors of residents' willingness to attempt rescue were evaluated using univariate analysis and multiple regression analysis. 


\section{Results}

\section{General Situation}

A total of 3000 questionnaires were distributed, which were all recovered on the spot, of which 2812 were valid; the valid response rate was $93.73 \%$. According to the survey, the residents in Nantong have a higher learning exposure to $\mathrm{CPR}$ than to $\mathrm{AED}$, the learning exposure rate of young people is higher than that of the middle-aged and elderly, and the awareness rates of AED and CPR in families in which there are members with heart disease are higher than for those in the families with no heart disease. The AED and CPR learning situation in relation to different demographic characteristics is presented in Table 1.

\section{BLS Awareness of Residents}

According to the survey, of the 2812 survey respondents, 41.18\% had seen an AED, but only 705 (25.07\%) had had experience of one and learned about their use; 31.73\% were aware of the effects of an AED, and $22.84 \%$ knew when to use one. In terms of CPR, residents' awareness levels were higher than for AEDs. Of the residents who had contacted and learned CPR, 45.08\% correctly can identify patients with cardiac and respiratory arrest, and $30.22 \%$ could correctly answer people who need CPR. Details are shown in Table 2. In terms of access to BLS knowledge, $31.06 \%$ of the respondents had obtained knowledge of AEDs from online platforms and 30.92\% from related lectures and training organized by their work

Table I Residents' Basic Learning Status of AED and Cardiopulmonary Resuscitation [n (\%)]

\begin{tabular}{|c|c|c|c|}
\hline Project & Cases & Contacted and Learned AED & Contacted and Learned CPR \\
\hline \multicolumn{4}{|l|}{ Age } \\
\hline 18-29 years & $740(26.31)$ & $214(28.92)$ & $435(58.78)$ \\
\hline $30-44$ years & $796(28.31)$ & $260(32.66)$ & $425(53.40)$ \\
\hline $45-59$ years & $691(24.57)$ & $|7|(24.75)$ & $3 I I(45.0 I)$ \\
\hline$\geq 60$ years & $585(20.8 I)$ & $60(10.26)$ & $202(34.52)$ \\
\hline \multicolumn{4}{|l|}{ Education level } \\
\hline Junior high school and below & $43 I(15.33)$ & $67(15.55)$ & $170(39.44)$ \\
\hline Senior high school & $974(34.64)$ & $221(22.69)$ & $4 \mid 4(42.5 I)$ \\
\hline University and college & $104 \mid(37.02)$ & $329(31.60)$ & $618(59.37)$ \\
\hline Postgraduate and above & $366(\mid 3.01)$ & $88(24.04)$ & $|7|(46.72)$ \\
\hline \multicolumn{4}{|l|}{ Occupation } \\
\hline Peasant & $209(7.43)$ & $9(4.31)$ & $75(35.89)$ \\
\hline General staff & $512(18.2 I)$ & $39(7.62)$ & $156(30.49)$ \\
\hline Student & $360(12.8 I)$ & $34(9.44)$ & $107(29.72)$ \\
\hline Teacher or civil servant & $412(14.65)$ & $63(15.30)$ & 197(47.82) \\
\hline Medicine and pharmacal staff & $905(32.18)$ & $520(47.46)$ & $722(79.78)$ \\
\hline Others & $4 \mid 4(\mid 4.72)$ & $40(9.66)$ & $116(28.02)$ \\
\hline \multicolumn{4}{|l|}{ Heart disease patient in the family } \\
\hline Yes & $1212(43.09)$ & $360(29.70)$ & $796(65.68)$ \\
\hline No & $1600(56.91)$ & $345(21.56)$ & $577(36.06)$ \\
\hline \multicolumn{4}{|l|}{ Have first aid experience or not } \\
\hline Yes & $667(23.73)$ & $24 I(36.13)$ & $445(66.7 I)$ \\
\hline No & $2145(76.28)$ & $464(21.63)$ & $928(43.26)$ \\
\hline
\end{tabular}

Table 2 BLS Awareness of Residents (n[\%])

\begin{tabular}{|l|c|c|c|c|c|}
\hline Group & AED Function (\%) & AED Use Timing (\%) & CPR Judgment Method (\%) & $\begin{array}{c}\text { CPR Applicable } \\
\text { Population (\%) }\end{array}$ & $\begin{array}{c}\text { Timing of } \\
\text { CPR (\%) }\end{array}$ \\
\hline Awareness & $221(31.37)$ & $161(22.84)$ & $619(45.08)$ & $415(30.22)$ & $610(44.43)$ \\
Unawareness & $484(68.63)$ & $544(77.16)$ & $754(54.92)$ & $958(69.78)$ & $763(55.57)$ \\
\hline
\end{tabular}


units, whereas $42.83 \%$ of respondents had obtained CPR knowledge from driving school training.

\section{Residents' Willingness to Attempt Rescue and Learn About BLS}

According to the survey statistics, in the face of accidents, 1420 respondents $(50.50 \%)$ were willing to attempt rescue, 1991 (70.80\%) were willing to attempt rescue under professional guidance, 2003 (71.23\%) were willing to attempt rescue after learning BLS techniques, and those with first aid experience were more willing to attempt rescue than those without first aid experience (the difference is statistically significant at $\mathrm{P}<0.05$ ). In terms of willingness to learn BLS techniques, people with a variety of different demographic characteristics had a high willingness to learn, and the difference is not statistically significant. Details are presented in Tables 3 and 4.

\section{Analysis of Influencing Factors of Residents Rescue}

A univariate analysis of the factors that influence residents to attempt rescue reveals that the differences related to

Table 3 Residents' Willingness to Rescue (n [\%])

\begin{tabular}{|l|c|c|c|}
\hline Group & Willing & Unwilling & Uncertain \\
\hline $\begin{array}{l}\text { Willingness to rescue } \\
\text { Willingness to rescue } \\
\text { under professional } \\
\text { guidance }\end{array}$ & $1420(50.50)$ & $216(7.68)$ & $1176(41.82)$ \\
$\begin{array}{l}\text { Willingness to rescue } \\
\text { after learning BLS }\end{array}$ & $2003(71.23)$ & $173(6.80)$ & $644(22.90)$ \\
\begin{tabular}{l} 
Willingness to learn BLS \\
\hline
\end{tabular} & $2077(73.86)$ & $178(6.33)$ & $657(19.81)$ \\
\hline
\end{tabular}

Table 4 Comparison of Residents' Willingness to Rescue with Different First Aid Experiences (n [\%])

\begin{tabular}{|l|c|c|c|}
\hline Group & $\begin{array}{c}\text { Willing } \\
\text { to } \\
\text { Rescue }\end{array}$ & $\begin{array}{c}\text { Willingness } \\
\text { to Rescue } \\
\text { Under } \\
\text { Professional } \\
\text { Guidance }\end{array}$ & $\begin{array}{c}\text { Willing to } \\
\text { Rescue } \\
\text { After } \\
\text { Learning } \\
\text { BLS }\end{array}$ \\
\hline $\begin{array}{l}\text { Residents with first aid } \\
\text { experience }\end{array}$ & $445(66.72)$ & $482(72.26)$ & $487(73.01)$ \\
\hline $\begin{array}{l}\text { Residents without first } \\
\text { aid experience }\end{array}$ & $975(45.45)$ & $1509(70.35)$ & $1516(70.68)$ \\
$\chi^{2}$ value & 92.014 & 0.902 & 1.357 \\
$P$ value & $<0.001$ & 0.342 & 0.244 \\
\hline
\end{tabular}

willingness to do so between different age groups, occupations, educational backgrounds, whether they have participated in first aid, and whether there are heart disease patients in the family are statistically significant $(\mathrm{P}<$ 0.05 ). With regard to willingness to attempt rescue under professional guidance, the differences between different age groups, occupations, educational backgrounds, and whether they have participated in first aid are also statistically significant $(\mathrm{P}<0.05)$. Furthermore, in relation to willingness to attempt rescue after learning BLS, the differences between different age groups, occupations, educational backgrounds, and whether they have participated in first aid are statistically significant $(\mathrm{P}<0.05$, Table 5). According to the results of single factor analysis, the community residents' willingness to rescue is used as the dependent variable, and the four factors of different age, occupation, education, and whether they have participated in first aid are used as independent variables to perform a multiple logistic regression analysis. Influencing factors, the details of which are presented in Table 6 .

\section{The Reasons Why Residents are Unwilling to Attempt Rescue}

Among the various reasons why residents are unwilling to attempt rescue in the face of emergencies are concern that their inadequate ability will cause harm to the patient $(32.75 \%)$, worry about legal issues $(27.91 \%)$, fear of contracting infectious diseases (14.01\%), an unwillingness to perform mouth-to-mouth artificial respiration (10.35\%), concern that people around them will complain (8.07\%), and an unwillingness to touch strangers (6.91\%).

\section{Discussion}

\section{Residents' Awareness of CPR is Better Than Their Awareness of AEDs}

According to the survey, $41.18 \%$ of residents had seen an AED. This may be related to the gradual increase in China's AED allocation rate in recent years, but only $25.07 \%$ of respondents had had experience of and learned about AEDs. Of these, the proportion of those who could correctly answer questions on AED-related knowledge correctly is much lower, which is related to the low rate of AED-related science popularization in China. This is similar to the results of a national survey in Singapore ${ }^{11}$ and reflects the large difference in the degree of AED expertise between residents of Asian countries and developed countries in Europe and America. ${ }^{8}$ In terms of CPR 
Table 5 Univariate Analysis on Influencing Factors of Residents' Willingness to Rescue ( \pm \pm SD, Points)

\begin{tabular}{|c|c|c|c|c|}
\hline Variable & Cases & $\begin{array}{c}\text { Score of } \\
\text { Willingness to } \\
\text { Rescue }\end{array}$ & $\begin{array}{l}\text { Score of Willingness to Rescue } \\
\text { Under Professional Guidance }\end{array}$ & $\begin{array}{c}\text { Score of Willingness to } \\
\text { Rescue After Learning } \\
\text { BLS }\end{array}$ \\
\hline \multicolumn{5}{|l|}{ Age } \\
\hline $18-29$ years & 740 & $2.53 \pm 0.52$ & $2.83 \pm 0.44$ & $2.74 \pm 0.46$ \\
\hline $30-44$ years & 796 & $2.43 \pm 0.57$ & $2.77 \pm 0.44$ & $2.7 I \pm 0.48$ \\
\hline $45-59$ years & 691 & $2.34 \pm 0.53$ & $2.67 \pm 0.49$ & $2.65 \pm 0.50$ \\
\hline$\geq 60$ years & 585 & $2.18 \pm 0.62$ & $2.58 \pm 0.52$ & $2.48 \pm 0.53$ \\
\hline$F$ value & & 7.393 & 4.461 & 5.557 \\
\hline$P$ value & & $<0.000$ & $<0.000$ & $<0.000$ \\
\hline \multicolumn{5}{|l|}{ Education level } \\
\hline Junior high school and below & 431 & $2.12 \pm 0.55$ & $2.66 \pm 0.52$ & $2.59 \pm 0.53$ \\
\hline Senior high school & 974 & $2.40 \pm 0.57$ & $2.70 \pm 0.48$ & $2.64 \pm 0.50$ \\
\hline University and college & $104 \mid$ & $2.56 \pm 0.57$ & $2.79 \pm 0.44$ & $2.74 \pm 0.46$ \\
\hline Postgraduate and above & 366 & $2.50 \pm 0.53$ & $2.83 \pm 0.40$ & $2.73 \pm 0.47$ \\
\hline$F$ value & & 18.390 & 9.164 & 7.923 \\
\hline$P$ value & & $<0.000$ & $<0.000$ & $<0.000$ \\
\hline \multicolumn{5}{|l|}{ Occupation } \\
\hline Peasant & 209 & $1.93 \pm 0.58$ & $2.5 I \pm 0.53$ & $2.47 \pm 0.54$ \\
\hline General staff & 360 & $2.26 \pm 0.57$ & $2.67 \pm 0.49$ & $2.62 \pm 0.50$ \\
\hline Student & 412 & $2.49 \pm 0.58$ & $2.82 \pm 0.43$ & $2.72 \pm 0.47$ \\
\hline Teacher or civil servant & 512 & $2.59 \pm 0.56$ & $2.85 \pm 0.35$ & $2.80 \pm 0.41$ \\
\hline Medicine and pharmacal staff & 905 & $2.64 \pm 0.53$ & $2.75 \pm 0.49$ & $2.73 \pm 0.51$ \\
\hline Others & 414 & $2.37 \pm 0.55$ & $2.67 \pm 0.48$ & $2.62 \pm 0.52$ \\
\hline$F$ value & & 14.252 & 4.341 & 3.549 \\
\hline$P$ value & & $<0.000$ & $<0.000$ & 0.02 \\
\hline \multicolumn{5}{|l|}{ Heart disease patient in the family } \\
\hline Yes & 1212 & $2.47 \pm 0.58$ & $2.73 \pm 0.48$ & $2.67 \pm 0.50$ \\
\hline No & 1600 & $2.38 \pm 0.59$ & $2.73 \pm 0.47$ & $2.66 \pm 0.50$ \\
\hline$t$ value & & 2.136 & -0.096 & 0.705 \\
\hline$P$ value & & 0.033 & 0.923 & 0.481 \\
\hline \multicolumn{5}{|l|}{ Have first aid experience or not } \\
\hline Yes & 667 & $2.65 \pm 0.56$ & $2.82 \pm 0.47$ & $2.78 \pm 0.49$ \\
\hline No & 2145 & $2.35 \pm 0.58$ & $2.70 \pm 0.47$ & $2.63 \pm 0.49$ \\
\hline$t$ value & & 6.046 & 3.019 & 3.394 \\
\hline$P$ value & & $<0.000$ & 0.003 & 0.001 \\
\hline
\end{tabular}

exposure, the overall level of awareness of CPR among Nantong urban residents is higher than that of AEDs. This may be related to the length and coverage of China's CPR science popularization, which is greater than for AEDs. Meanwhile, residents' judgment of CPR, who it should be applied to, and the timing of use, is not positive, and there are even major misunderstandings. This highlights the fact that, in the popularization of knowledge of CPR, in addition to teaching residents CPR practice, we must also pay attention to the education and publicity of CPR-related theoretical knowledge to improve residents' correct understanding of CPR so as not to cause unnecessary harm to the patient.

\section{Analysis of the Reasons for the Low Activation Rate of Residents' AED}

The unreasonable configuration of AED may also result in low access rate. According to the survey, offices, schools, and sports venues are areas with high incidence of OHCA. In recent years, my country's AED configuration has been vigorously developed. Since 2017, the Nantong Municipal Government has launched a project to deploy external 
Table 6 Multiple Logistic Regression Analysis on Influencing Factors of Residents' Willingness to Rescue

\begin{tabular}{|l|c|c|c|c|}
\hline Variable & B & S.E & P & Exp (B) \\
\hline Age & & & 0.043 & \\
45-59 years & 0.419 & 0.395 & 0.288 & 1.521 \\
$30-44$ years & 0.683 & 0.408 & 0.094 & 1.980 \\
I8-29 years & -0.309 & 0.407 & 0.449 & 0.734 \\
\hline Education level & & & 0.063 & \\
Senior high school & 0.616 & 0.351 & 0.079 & 1.852 \\
University and college & 0.588 & 0.298 & 0.048 & 1.800 \\
Postgraduate and above & 0.094 & 0.435 & 0.829 & 1.098 \\
\hline Occupation & & & 0.003 & \\
General staff & 0.820 & 0.342 & 0.017 & 2.269 \\
Student & 0.718 & 0.290 & 0.013 & 2.051 \\
Teacher or civil servant & 1.301 & 0.441 & 0.003 & 3.673 \\
Medicine and pharmacal staff & 1.041 & 0.335 & 0.002 & 2.831 \\
Others & 0.803 & 0.328 & 0.014 & 2.232 \\
\hline Have first aid experience or not: & 0.966 & 0.209 & 0.007 & 2.628 \\
Yes & & & & \\
\hline Constant & -1.708 & 0.488 & 0.000 & 0.181 \\
\hline
\end{tabular}

automatic defibrillators in key public places outside medical institutions. So far, it has been used in key public places in the city: shopping malls, schools, office buildings, In hotels and other areas, 140 AEDs were installed, of which 100 were newly added in 2019. However, due to the imperfect social science work of AEDs, residents have a low level of AED mastery, and most non-medical workers do not know how to obtain AEDs, resulting in the failure of the public to increase the use rate of AEDs. The survey found that the use rate of AEDs in Nantong City was zero in the past four years, which is consistent with the results of a large sample survey of AEDs used in different occupational groups in Japan. However, in a PAD study in the United States and Canada, their feasibility is higher. Contrary to Asian countries, it once again reflects that Asians have some obstacles in using AED.

\section{Network Platform and Professional Lectures are Important Ways to Promote BLS}

According to the survey of learning pathways, $61.98 \%$ of residents had obtained AED knowledge from online platforms and related lectures and training, $24.4 \%$ and $42.83 \%$ of residents had obtained CPR knowledge from related lectures and driving school training, respectively, while only a small number of people had obtained BLS knowledge from newspapers and books. This suggests that the Internet is the preferred way to promote first aid skills such as BLS. In addition, relevant lectures and training organized by work units, schools, driving schools, etc. are also an important way for residents to learn BLS. However, in the present study, it was found that although $48.23 \%$ of residents admitted to having learned CPR skills, only a small number could correctly answer questions on CPR-related knowledge. This means that we must attach importance to the quality of training in various network Promotional programs, and in those organized by driving schools and corporate units, to ensure the accuracy and effectiveness of the training.

\section{Residents' Willingness to Attempt Rescue and Learn is Highly Active}

According to the survey, different school ages, educational backgrounds, occupations, and whether they have participated in CPR are important factors that affect whether residents are willing to attempt rescue when an emergency occurs. The higher the level of education and the younger the age, the higher the residents' willingness to attempt rescue. This may be related to the higher acceptance of new knowledge, greater access to information, and physical factors. This is consistent with the results of a study in the United States ${ }^{12}$ those who have participated in CPR are more willing to attempt rescue than those who have not. The reason for this may be that they have personal experience and a better understanding of the importance of first aid. For residents of some families with heart disease patients, their willingness to rescue in the face of accidents may increase. The reason may be that they know the importance of timely BLS rescue for patients with cardiac arrest. The percentage of those who are willing to attempt rescue under professional guidance and of those who are willing to attempt rescue after learning BLS techniques is significantly higher than those without guidance and training, and in terms of cause, the primary reason given by residents for why they are unwilling to rescue patients is because they are worried that they do not have sufficient capabilities to avoid causing secondary harm to the patient. In terms of willingness to learn, residents have a strong enthusiasm for BLS learning, and most of those who are unwilling to attempt rescue cite the lack of relevant skills and knowledge. This means that increasing residents' BLS knowledge reserve can increase residents' willingness to attempt rescue. Kim et al found that 
residents' first aid skills can be improved through training. ${ }^{13}$ If the respondents have experience of participating in or performing first aid, their willingness to attempt rescue is higher than those who have no such experience. Worrying about legal issues is the second major factor affecting the willingness to attempt rescue. These factors remind us that while propagating the knowledge of BLS, we need to strengthen the importance of "first witnesses" in rescue $e^{3,14,15}$ and the popularization of related laws, as a study has revealed that the survival rate of patients who have CPR after AED defibrillation performed by the first witness was higher than that of patients who waited for professionals to arrive before AED defibrillation was performed or who did not receive defibrillation. $^{16}$ In addition, unwillingness to breathe mouth-to-mouth and fear of infectious diseases are also important reasons why residents are unwilling to attempt rescue. According to the 2020 American Heart Association guidelines, non-professionals can use simple compression instead of traditional CPR (chest compression plus artificial respiration) to improve the survival rate of OHCA patients. ${ }^{17}$ A study revealed that ${ }^{18}$ witnesses can even simply give continuous chest compressions instead of standard CPR to provide emergency treatment for OHCA patients. It is clear that we can improve on traditional methods when conducting BLS training, focusing on the use of chest compressions and AEDs so as to improve the residents' BLS expertise and willingness to attempt rescue.

OHCA has become a global public health problem, ${ }^{19}$ and it is the leading cause of death from cardiovascular disease in China in recent years. ${ }^{20}$ The early rescue of OHCA patients using BLS is the primary measure to improve the survival rate of patients. Since 2017, Nantong City has deployed AEDs in major public places in urban areas and provided training for local staff. The current delivery volume is 140 machines, but so far, the utilization rate of AEDs is zero. In August 2020, the Chinese Red Cross Society and the Ministry of Education jointly issued a notice to incorporate student health knowledge and first aid, especially CPR, into the education curriculum. This notice has received a positive response on the Internet. This study reveals that the residents of Nantong City have a low level of awareness of BLS, which may be the main reason for the low utilization rate of AEDs. However, they express a strong willingness to learn and attempt rescue, indicating that BLS publicity should not be delayed. This survey is limited to the urban area of Nantong city, so there are certain limitations in geographical scope. In the future, the scope of the survey can be expanded further to make data sources more representative.

\section{Ethics Approval and Consent to Participate}

This study was approved by the ethics committee of the first people's Hospital of Nantong City, and informed consent was obtained from the respondents. This study was conducted in accordance with the declaration of Helsinki.

\section{Consent for Publication}

All participants signed a document of informed consent.

\section{Acknowledgments}

We would like to acknowledge the hard and dedicated work of all the staff that implemented the intervention and evaluation components of the study.

\section{Funding}

Nantong Municipal Health Commission Project. Project number: JCZ20159. Project Name: Residents' basic life support rescue willingness.

\section{Disclosure}

The authors declare that they have no competing interests.

\section{References}

1. McNally B, Robb R, Mehta M, et al. Centers for Disease Control and Prevention. Out-of-hospital cardiac arrest surveillance -- Cardiac Arrest Registry to Enhance Survival (CARES), United States, October 1, 2005--December 31, 2010. MMWR Surveill Summ. 2011;60(8):1-19.

2. Gu XM, Yao SB, He ZJ, Wang YG, Li ZH. Meta-analysis of the success rate of heartbeat recovery in patients with prehospital cardiac arrest in the past 40 years in China. Mil Med Res. 2020;7(1):34. doi:10.1186/s40779-020-00263-7

3. Zhao P, Bi C, Jiang T, et al. Superiority of cardiopulmonary resuscitation plus automated external defibrillator used by first-responders on patients with out-of-hospital cardiac arrests: a meta-analysis. Chin J Critical Care Med. 2018;38(4):350-356.

4. Xu F, Zhang Y, Chen Y. Cardiopulmonary Resuscitation Training in China: current Situation and Future Development. JAMA Cardiol. 2017;2(5):469-470. doi:10.1001/jamacardio.2017.0035

5. Riva G, Ringh M, Jonsson M, et al. Survival in Out-of-Hospital Cardiac Arrest After Standard Cardiopulmonary Resuscitation or Chest Compressions Only Before Arrival of Emergency Medical Services: nationwide Study During Three Guideline Periods. Circulation. 2019;139(23):2600-2609. doi:10.1161/CIRCULATIONAHA.118.038 179

6. Kishimori T, Kiguchi T, Kiyohara K, et al. Public-access automated external defibrillator pad application and favorable neurological outcome after out-of-hospital cardiac arrest in public locations: a prospective population-based propensity score-matched study. Int J Cardiol. 2020;299:140-146. doi:10.1016/j.ijcard.2019.07.061 
7. Panchal AR, Bartos JA, Cabañas JG, Adult Basic and Advanced Life Support Writing Group. Part 3: adult Basic and Advanced Life Support: 2020 American Heart Association Guidelines for Cardiopulmonary Resuscitation and Emergency Cardiovascular Care. Circulation. 2020;142(16_suppl_2):S366-S468. doi:10.1161/ CIR.0000000000000916

8. Ni S, Zhu J, Li S, Jin X. Investigation on the use and awareness of automatic external defibrillator in Chinese residents. Chin General Practice. 2019;22(9):3171-3174.

9. Zou X, Qing H. Report on residenis' atttude, knowlwdge and action towards emergency treatment on spot in community of wuxi city. Modern Preven Med. 2016;33(12):2404-2405.

10. Huang Y, Wang H, Zhou X, Liu F. Investigation on knowledge, attitude and practice status quo about cardiopulmonary resuscitation in primary caregivers for patients with high risk of sudden cardiac death. Chongqing Med. 2017;46(21):2955-2958.

11. Ong ME, Quah JL, Ho AF, et al. National population based survey on the prevalence of first aid, cardiopulmonary resuscitation and automated external defibrillator skills in Singapore. Resuscitation. 2013;84(11):1633-1636. doi:10.1016/j.resuscitation.2013.05.008

12. Owen DD, McGovern SK, Murray A, et al. Association of race and socioeconomic status with automatic external defibrillator training prevalence in the United States. Resuscitation. 2018;127:100-104. doi:10.1016/j.resuscitation.2018.03.037

13. Kim EJ, Roh YS. Competence-based training needs assessment for basic life support instructors. Nurs Health Sci. 2019;21(2):198-205. doi:10.1111/nhs.12581

14. Kelly CM, Jorm AF, Kitchener BA, Langlands RL. Development of mental health first aid guidelines for deliberate non-suicidal self-injury: a Delphi study. BMC Psychiatry. 2008;8:62. doi:10. 1186/1471-244X-8-62
15. Jiang Y, Wu B, Long L, Li J, Jin X. Attitudes and willingness toward out-of-hospital cardiopulmonary resuscitation: a questionnaire study among the public trained online in China. BMJ Open. 2020;10(10): e038712. doi:10.1136/bmjopen-2020-038712

16. Weisfeldt ML, Sitlani CM, Ornato JP, et al., ROC Investigators. Survival after application of automatic external defibrillators before arrival of the emergency medical system: evaluation in the resuscitation outcomes consortium population of 21 million. $J$ Am Coll Cardiol. 2010;55(16):1713-1720. doi:10.1016/j. jacc.2009.11.077

17. He Y, Zheng Y, Zhou F, et al. Interpretation of the 2020 American Heart Association Cardiopulmonary Resuscitation and Cardiovascular First Aid Guidelines-Adult Basic/Advanced Life Support. Huaxi Med. 2020;11:1311-1323.

18. Zhan L, Yang LJ, Huang Y, He Q, Liu GJ. Continuous chest compression versus interrupted chest compression for cardiopulmonary resuscitation of non-asphyxial out-of-hospital cardiac arrest. Cochrane Database Syst Rev. 2017;3(3):CD010134. doi:10.1002/ 14651858.CD010134.pub2

19. Kelham M, Jones TN, Rathod KS, et al. An observational study assessing the impact of a cardiac arrest centre on patient outcomes after out-of-hospital cardiac arrest (OHCA). Eur Heart J Acute Cardiovasc Care. 2020;9(4_suppl):S67-S73. doi:10.1177/204887262 0974606

20. Jiang Y, Yang C, Deng X, Li Z, Li S. Comprehensive Analysis, Discussion and Suggestion on the Current Situation of Cardiopulmonary Resuscitation and Automatic External Defibrillator in General Public in China. J Adv Med Sci. 2021;4 (1):16-18. doi:10.30564/jams.v4i1.2719
Risk Management and Healthcare Policy

\section{Publish your work in this journal}

Risk Management and Healthcare Policy is an international, peerreviewed, open access journal focusing on all aspects of public health, policy, and preventative measures to promote good health and improve morbidity and mortality in the population. The journal welcomes submitted papers covering original research, basic science, clinical \& epidemiological studies, reviews and evaluations,

\section{Dovepress}

guidelines, expert opinion and commentary, case reports and extended reports. The manuscript management system is completely online and includes a very quick and fair peer-review system, which is all easy to use. Visit http://www.dovepress.com/testimonials.php to read real quotes from published authors. 